\title{
Land snail genus Sarika Godwin-Austen, 1907 (Eupulmonata: Ariophantidae) from Cambodia, with description of three new species
}

\author{
Arthit PHOLYOTHA ${ }^{1}$, Chirasak SUTCHARIT ${ }^{2}$, Phanara THACH ${ }^{3}$, Samol $\mathrm{CHHUOY}^{4}$, \\ Peng Bun NGOR ${ }^{5} \&$ Somsak PANHA ${ }^{6, *}$ \\ ${ }^{1}$ Biological Sciences Program, Faculty of Science, Chulalongkorn University, \\ Bangkok 10330, Thailand. \\ ${ }^{1,2,6}$ Animal Systematics Research Unit, Department of Biology, Faculty of Science, \\ Chulalongkorn University, Bangkok 10330, Thailand. \\ 3,4,5 Inland Fisheries Research and Development Institute (IFReDI), \\ Fisheries Administration Phnom Penh, Cambodia. \\ ${ }^{5}$ Wonders of the Mekong Project, c/o IFReDI, \#186, Norodom Blvd., Phnom Penh, Cambodia.
}

*Corresponding author: somsak.pan@chula.ac.th

1Email: arthitpolyotha@gmail.com

${ }^{2}$ Email: jirasak4@yahoo.com

${ }^{3}$ Email: thachphanara@yahoo.com

${ }^{4}$ Email: chhuoysamol@yahoo.com

${ }^{5}$ Email: pengbun.ngor@gmail.com

\footnotetext{
${ }^{1}$ urn:1sid:zoobank.org:author:6CC9B5FE-6586-4132-8289-102DC14D3844

${ }^{2}$ urn:lsid:zoobank.org:author:C2E2FA6B-A3F9-4F33-B447-B59B1BD322D4

${ }^{3}$ urn:1sid:zoobank.org:author:CA9CDCEC-E5BB-452A-9C6C-18F3280AAC02

${ }^{4}$ urn:1sid:zoobank.org:author:2674B4EE-7B30-4285-8543-A46FD1E5B53E

${ }^{5}$ urn:1sid:zoobank.org:author:77BC565D-7067-46C6-8744-A0C50A6E2B3F

${ }^{6}$ urn:1sid:zoobank.org:author:AC935098-D901-4F35-A414-4B0D4FE44E79
}

\begin{abstract}
Taxonomic work on the land snail genus Sarika Godwin-Austen, 1907 in Cambodia is scarce. A total of three species were recognized from Cambodia prior to this study. However, their taxonomic descriptions were based mainly on shell morphology, with limited genital data. To address this knowledge gap, we opportunistically surveyed for land snails in Cambodia. Our inventory yielded four species of Sarika - one recognized species, Sarika bocourti (Morelet, 1875), from Battambang Province and three new species, Sarika khmeriana Pholyotha \& Panha sp. nov., Sarika lactoconcha Pholyotha \& Panha sp. nov. and Sarika nana Pholyotha \& Panha sp. nov. from Kampot and Takeo Provinces in southern Cambodia. Our discovery involves the first species of Sarika to be described from Cambodia in more than a century highlights the extent to which the diversity of Cambodian land snails remains to be discovered. The status of two species, Sarika benoiti (Crosse \& Fischer, 1863) and Sarika resplendens (Philippi, 1846), is at present ambiguous because no material identifiable as these species was found in recent extensive surveys. Although $S$. bocourti was recently collected from Cambodia,
\end{abstract}


its taxonomic position remained unclear due to a lack of living specimens. Detailed descriptions and illustrations of living animals, shell morphology and reproductive anatomy are provided, and a map showing their distributions is given.

Keywords. Pulmonata, endemic, Indochina, Mekong Delta, limestone, taxonomy.

Pholyotha A., Sutcharit C., Thach P., Chhuoy S., Ngor P.B. \& Panha S. 2020. Land snail genus Sarika GodwinAusten, 1907 (Eupulmonata: Ariophantidae) from Cambodia, with description of three new species. European Journal of Taxonomy 674: 1-21. https://doi.org/10.5852/ejt.2020.674

\section{Introduction}

The genus Sarika Godwin-Austen, 1907 is classified in the family Ariophantidae Godwin-Austen, 1888 (Schileyko 2002). It is recognized as a group of common ground-dwelling snails that are distributed throughout mainland Southeast Asia (Blanford \& Godwin-Austen 1908; Zilch 1959; Solem 1966; Schileyko 2002). Traditionally, the genus Sarika is characterized by its relatively large, depressed and yellowish or brownish polished shell (Godwin-Austen 1907; Pholyotha et al. 2020). However, species level identifications based solely on shells have proven to be problematic owing to a lack of distinguishing characters. Conversely, the genital apparatus with its straight (or un-coiled) epiphallic caecum is considered to be a significant character that can separate Sarika from the sibling genus, Macrochlamys Gray, 1847 (Godwin-Austen 1907; Blanford \& Godwin-Austen 1908; Schileyko 2002, 2003; Sutcharit \& Panha 2008; Pholyotha et al. 2018, 2020). The similarities of shell traits in different lineages suggest that taxonomic classification must also take into account examination of the genitalia, which is usually accepted as more reliable than shell morphology (Solem 1966; Liew et al. 2009; Hyman \& Ponder 2010, 2016; Pholyotha et al. 2018, 2020).

Since the genus Sarika was established, at least 24 nominal species have been reported (see Table 1; Hemmen \& Hemmen 2001; Maassen 2001; Fischer \& Dautzenberg 1904; Blanford \& Godwin-Austen 1908; Inkhavilay et al. 2019; Pholyotha et al. 2018, 2020). The species recorded from Malaysia, Myanmar and Thailand have been systematically revised (Laidlaw 1933; Solem 1966; Maneevong 2000; Sutcharit \& Panha 2008; Pholyotha et al. 2020), whereas four species from Laos and two species from Vietnam have only been listed without any genital information (Schileyko 2011; Inkhavilay et al. 2019). In Cambodia, the genus Sarika was neglected, and the historical literature (Fischer 1891; Fischer \& Dautzenberg 1904) mentioned three species of Sarika possibly occurring in this country, under the genus Nanina, "N." resplendens (Philippi, 1841), "N." benoiti (Crosse \& Fischer, 1863) and "N." bocourti (Morelet, 1875). Unfortunately, all these species are only represented by shells, and such limited samples have resulted in misidentifications, and without precise collection localities.

Recent field collections from karstic and non-karstic habitats in southern Cambodia have yielded a number of ariophantid snails that could be classified into the genus Sarika. They are all clearly distinct from all other known members of the species complex of Sarika-Macrochlamys from Myanmar, Thailand, Laos and Vietnam. Therefore, we describe three new species of Sarika herein based on shell, external morphology, radula, genitalia and spermatophore characters. Additionally, the diagnostic characters of three previously recorded species in Cambodia, S. resplendens, S. benoiti and S. bocourti are also provided. This information further supports the growing knowledge of the diverse terrestrial snail fauna in Cambodia.

\section{Material and methods}

We collected snail samples from karstic and non-karstic habitats in southern Cambodia (Fig. 1). Photographs of living snails were taken using a Nikon camera (DSLR D850) with a macro lens. 
Table 1. Taxa attributed to Macrochlamys and Sarika from mainland Southeast Asia, as classified by their maximum shell width and maximum whorl numbers. Data are taken from the original descriptions and additional references. Taxa in bold are confirmed in generic placement by genital characters. ${ }^{1}$ GodwinAusten (1907) and Blanford \& Godwin-Austen (1908); ${ }^{2}$ Laidlaw (1933); ${ }^{3}$ Solem (1966); ${ }^{4}$ Maneevong (2000); ${ }^{5}$ Sutcharit \& Panha (2008): ${ }^{6}$ Pholyotha et al. (2018); ${ }^{7}$ Pholyotha et al. (2020); ${ }^{8}$ This study.

\begin{tabular}{|c|c|c|c|c|}
\hline & \multicolumn{4}{|c|}{ Maximum number of whorls ( $x$ ) } \\
\hline & $<5$ & $5 \leq x<6$ & $6 \leq x<7$ & $\geq 7$ \\
\hline $\begin{array}{l}\text { Small size } \\
\text { (shell width } \leq 10 \mathrm{~mm} \text { ) }\end{array}$ & $\begin{array}{l}\text { M. kumahensis } \\
\text { M. patens } \\
\text { M. pauxillula } \\
\text { M. perpaula }\end{array}$ & $\begin{array}{c}\text { M. bartoni } \\
\text { M. brachystia }{ }^{7} \\
\text { M. brunnea } \\
\text { M. callojuncta } \\
\text { M. cauisa } \\
\text { M. curvilabris } \\
\text { M. hatchongi } \\
\text { M. noxia } \\
\text { M. petasus }{ }^{7} \\
\text { M. poongee } \\
\text { M. rejectella } \\
\text { M. salwinensis } \\
\text { M. spreta } \\
\text { M. subpetasus }\end{array}$ & $\begin{array}{l}\text { M. euspira } \\
\text { M. jousoufi }\end{array}$ & M. ramburianus \\
\hline $\begin{array}{l}\text { Medium size } \\
(10 \mathrm{~mm}<\text { shell width }< \\
20 \mathrm{~mm})\end{array}$ & - & $\begin{array}{c}\text { M. } \text { aurantia }^{6} \\
\text { M. chaos } \\
\text { M. } \text { coleus }^{6} \\
\text { M. declivis } \\
\text { M. hypoleuca } \\
\text { M. malaccana } \\
\text { M. psyche } \\
\text { M. tanymentula } \\
\text { M. zero } \\
\text { S. nana } \text { sp. nov. } \\
\text { S. planata } \\
\end{array}$ & $\begin{array}{l}\text { M. aspides }{ }^{7} \\
\text { M. } \text { caverna }^{6} \\
\text { M. excepta } \\
\text { M. lemma }{ }^{6} \\
\text { M. nebulosa } \\
\text { M. stenogyra } \\
\text { M. stephoides } \\
\text { S. asamurai }{ }^{5} \\
\text { S. benoiti } \\
\text { S. diadema }\end{array}$ & $\begin{array}{l}\text { M. notha } \\
\text { S. } \text { concavata }^{7} \\
\text { S. } \text { consepta }^{7} \\
\text { S. dugasti }{ }^{4} \\
\text { S. subcornea }\end{array}$ \\
\hline $\begin{array}{l}\text { Large size } \\
\text { (shell width } \geq \mathbf{2 0} \mathbf{~ m m} \text { ) }\end{array}$ & - & $\begin{array}{l}\text { M. douvillei } \\
\text { M. glyptorhaphe } \\
\text { M. tenuigranosa }\end{array}$ & $\begin{array}{l}\text { M. } \text { kelantanensis }^{6,7} \\
\text { S. birmana } \\
\text { S. dohrniana } \\
\text { S. } \text { khmeriana } \text { sp. nov. }^{8} \\
\text { S. lactoconcha } \text { sp. nov. }^{8} \\
\text { S. limbata } \\
\text { S. lopa }{ }^{7} \\
\text { S. obesior } \\
\text { S. resplendens }{ }^{1} \\
\text { S. rex }\end{array}$ & $\begin{array}{l}\text { M. despecta } \\
\text { S. bocourti } \\
\text { S. hainesi }{ }^{3} \\
\text { S. heptagyra } \\
\text { S. kawtaoensis } \\
\text { S. ochtogyra } \\
\text { S. pumicata }\end{array}$ \\
\hline
\end{tabular}

Samples were euthanized by a two-step method following the AVMA Guidelines for the Euthanasia of Animals (American Veterinary Medical Association 2020) and fixed in 70\% (v/v) ethanol for anatomical examination. Species identification followed original descriptions and comparison with the relevant type specimens. Each species (3-10 specimens) was dissected and examined under an Olympus SZX2TR30 stereoscopic light microscope and then imaged by Nikon camera. Inner sculpture of genitalia was imaged by a stereo microscope with Cell'D Imaging Software. Shells were imaged by digital camera. Shell whorls were counted and measured using a vernier caliper. Radulae were extracted, soaked in $10 \%$ 
$(\mathrm{w} / \mathrm{v})$ sodium hydroxide, cleaned with distilled water under stereoscopic light microscope, and then imaged by scanning electron microscopy (SEM; JEOL, JSM-6610 LV).

\section{Institutional abbreviations}

CUMZ $=$ Chulalongkorn University Museum of Zoology, Bangkok, Thailand

$\mathrm{NHM}=$ Natural History Museum London, United Kingdom

ZRC $=$ Zoological Reference Collection of the Lee Kong Chian Natural History Museum, National University of Singapore, Singapore

\section{Abbreviations for morphological terms}

In the species descriptions, the term 'proximal' refers to the region closest to the genital opening, whereas 'distal' refers to the region furthest away from the genital opening. The following abbreviations are used in the descriptions of anatomy as described in Pholyotha et al. $(2018,2020)$.

$$
\begin{aligned}
\text { at } & =\text { atrium } \\
\mathrm{da} & =\text { dart apparatus } \\
\mathrm{e} & =\text { epiphallus } \\
\mathrm{ec} & =\text { epiphallic caecum } \\
\mathrm{fl} & =\text { flagellum } \\
\mathrm{fo} & =\text { free oviduct } \\
\mathrm{gd} & =\text { gametolytic duct } \\
\mathrm{gs} & =\text { gametolytic sac } \\
\mathrm{hf} & =\text { head filament } \\
\mathrm{p} & =\text { penis } \\
\mathrm{pc} & =\text { penial caecum } \\
\mathrm{pp} & =\text { penial pilaster } \\
\mathrm{prm} & =\text { penial retractor muscle } \\
\mathrm{pv} & =\text { penial verge } \\
\mathrm{ss} & =\text { sperm sac } \\
\mathrm{tf} & =\text { tail filament } \\
\mathrm{v} & =\text { vagina } \\
\mathrm{vd} & =\text { vas deferens }
\end{aligned}
$$

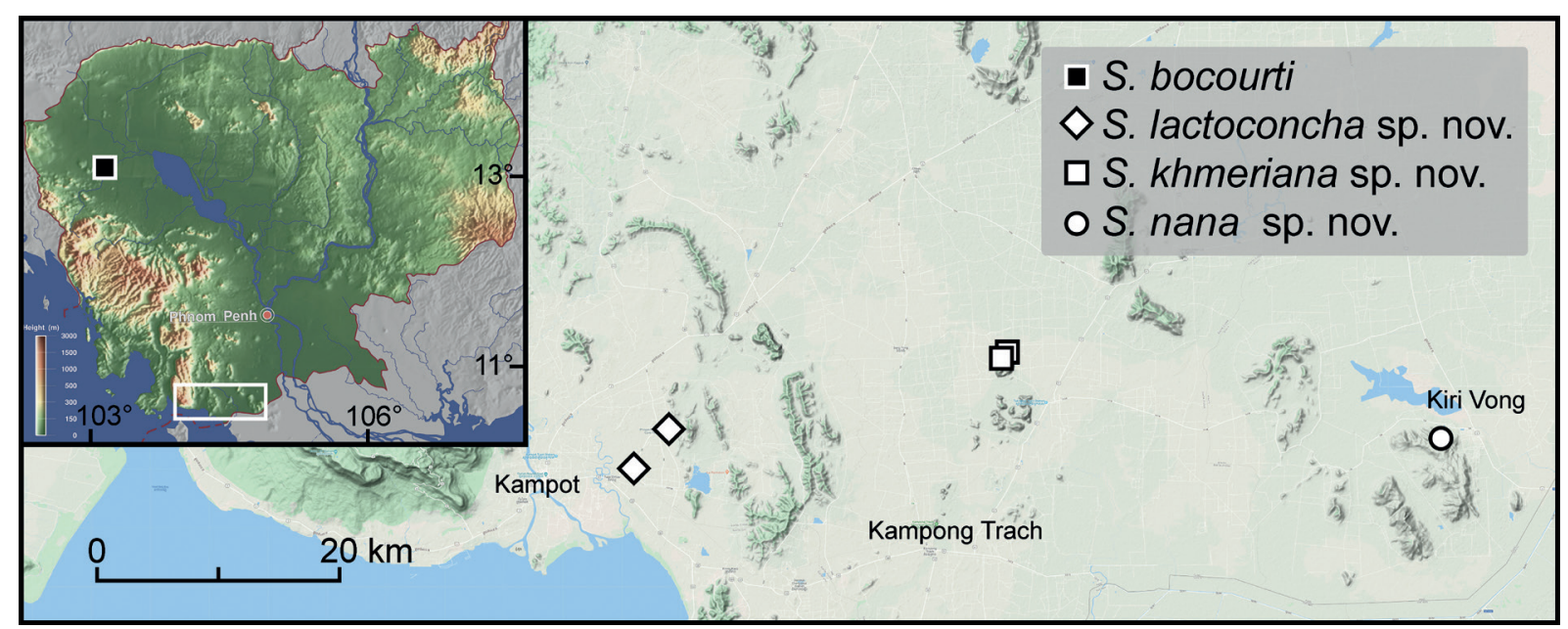

Fig. 1. Geographic distribution of Sarika spp. in Cambodia based on new specimens examined herein. (modified from GinkgoMaps-project http://www.ginkgomaps.com). 


\section{Taxon names}

The descriptions and new taxon names described herein are the responsibility of A. Pholyotha and S. Panha, and the authorship of the new taxa names should be cited as:

Sarika lactoconcha Pholyotha \& Panha sp. nov. in Pholyotha et al. 2020.

Sarika khmeriana Pholyotha \& Panha sp. nov. in Pholyotha et al. 2020.

Sarika nana Pholyotha \& Panha sp. nov. in Pholyotha et al. 2020.

\section{Results}

\section{Taxonomy}

Family Ariophantidae Godwin-Austen, 1888

Subfamily Macrochlamydinae Godwin-Austen, 1888

Genus Sarika Godwin-Austen, 1907

Sarika Godwin-Austen, 1907: 179. — Blanford \& Godwin-Austen 1908: 276. — Zilch 1959: 325. — Schileyko 2002: 1288. — Pholyotha et al. 2020.

\section{Type species}

Helix resplendens Philippi, 1846, by original designation.

Sarika resplendens (Philippi, 1846)

Table 1; Fig. 2A

Helix resplendens Philippi, 1846: 192. Type locality: Prope Mergui Indiae Orientalis (Mergui Islands, Myeik District, Tanintharyi Region, Myanmar).

Helix resplendens - Pfeiffer 1848: 56; 1849: 227-228, pl. 110, figs 7-9; 1868: 100. — Hanley \& Theobald 1872: 24, pl. 51, fig. 4.

Macrochlamys resplendens - Godwin-Austen 1883: 109-110, pl. 26, figs 1-3. - Godwin-Austen 1898: 49-50. - Collinge 1903: 209. — Panha 1996: 34; 1997: 52, fig. 14.

Nanina (Macrochlamys) resplendens - Tryon 1886: 91, pl. 30, figs 73-76. — Fischer \& Dautzenberg 1904: 395.

Ariophanta (Macrochlamys) resplendens - Fischer 1891: 21.

Sarika resplendens - Godwin-Austen 1907: 179-181, pl. 111, figs 3, 3a, pl. 116, figs 2, 2a-2b. Blanford \& Godwin-Austen 1908: 277-278, fig. 84. — Fischer 1973: 92. — Maassen 2001: 113.

- Hemmen \& Hemmen 2001: 45. - Sutcharit \& Panha 2008: 96. — Schileyko 2011: 34. — Inkhavilay et al. 2019: 82, figs 39a, 57a. — Pholyotha et al. 2020.

Sarica [sic] resplendens - Fischer 1973: 92.

\section{Diagnosis}

Shell depressed, large (shell width $22.1 \mathrm{~mm}$, shell height $10.5 \mathrm{~mm}$ ), rather thin, semi-translucent and pale yellowish brown. Shell surface smooth and glossy; more glossy below the periphery; suture impressed; spire slightly elevated. Entire shell consisting of $6 \frac{1}{2}$ regularly increasing whorls. Periphery of body whorl rounded. Aperture obliquely oval-lunate shaped; peristome simple. Columellar margin simple and slightly reflected near umbilicus. Umbilicus narrowly opened and deep. 


\section{Material examined}

CAMBODIA • 1 shell; H. Adam ex. Godwin-Austen collection; NHMUK 1903.7.1.112.

\section{Remarks}

Sarika resplendens is a widely distributed species and has been recorded throughout mainland Southeast Asia (Collinge 1903; Fischer 1973; Schileyko 2011; Inkhavilay et al. 2019). This species is found commonly in Thailand (Pholyotha personal observation) and Laos (Inkhavilay et al. 2019). GodwinAusten (1883: 110, pl. 26, fig. 2) first reported this species from Cambodia without a precise location. The description of this shell morphology agrees well with the typical $S$. resplendens from Myanmar (see Pholyotha et al. 2020 for comparison), and we provide a brief description herein based on this specimen. Later, Fischer \& Dautzenberg (1904: 395) mentioned the specimen identified as S. resplendens from "Kébal-Roméas, Cambodge (Pavie)", without illustration. We have visited this limestone outcrop, Phnom Kbal Romeas, and found one Sarika species that clearly differs from S. resplendens s.s. and is described herein as a new species (for further comparison with this species see under S. lactoconcha Pholyotha \& Panha sp. nov.).

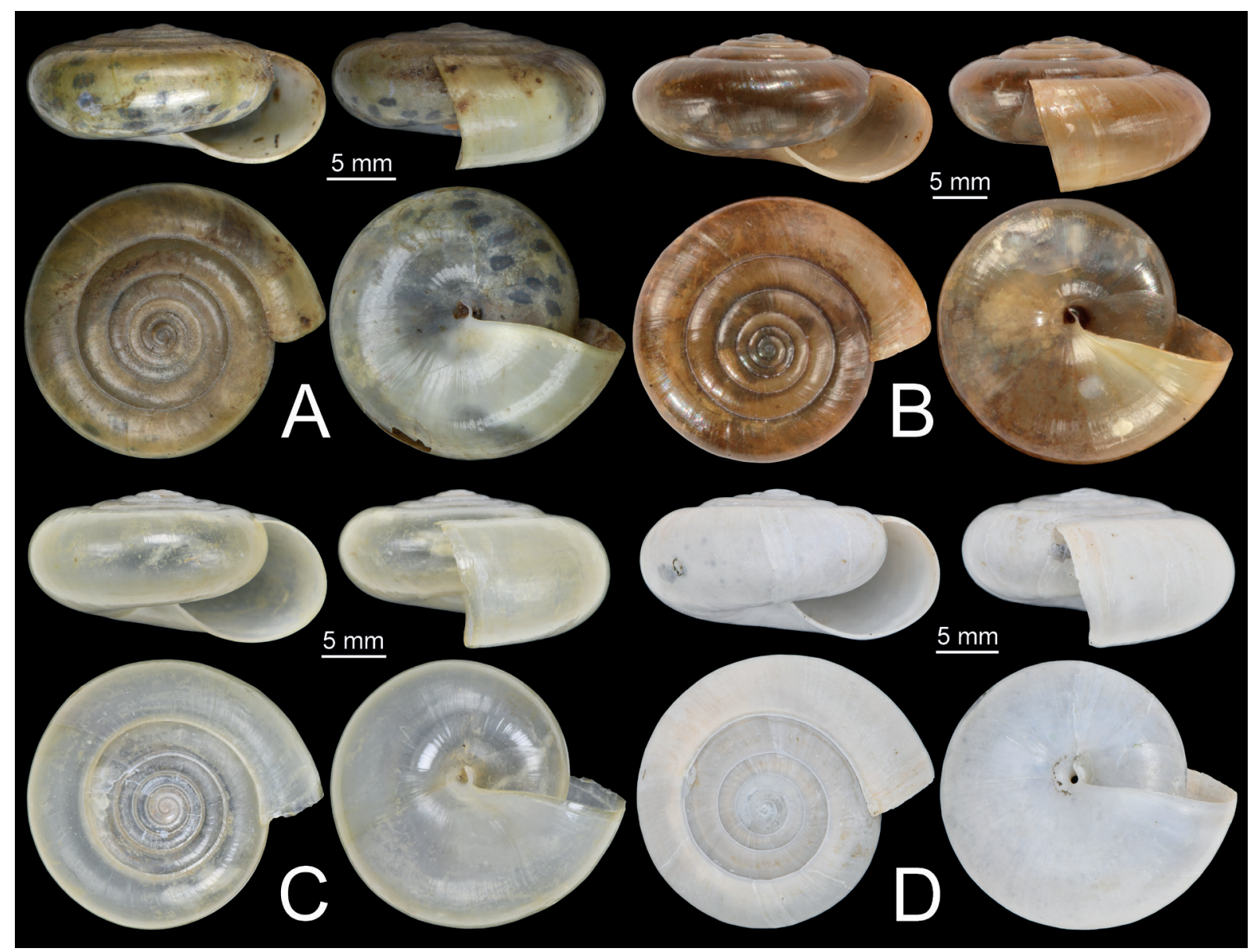

Fig. 2. Shells of Sarika spp. A. Sarika resplendens (Philippi, 1846) (NHMUK 1903.7.1.112). B. S. bocourti (Morelet, 1875) (CUMZ 7900). C. S. lactoconcha Pholyotha \& Panha sp. nov., holotype (CUMZ 7901). D. S. lactoconcha Pholyotha \& Panha sp. nov., paratype (CUMZ 7902). 
Zonites benoiti Crosse \& Fischer, 1863: 346, pl. 14, fig. 4. Type locality: in loco Fuyen-Moth dicto, Cochinchine (Phu Yen Province, Vietnam).

Helix benoiti - Pfeiffer 1868: 99. - Morelet 1875: 248.

Nanina (Macrochlamys) benoiti - Tryon 1886: 90, pl. 30, figs 57-58. — Fischer \& Dautzenberg 1904: 394.

Ariophanta (Macrochlamys ?) benoiti - Fischer 1891: 20.

Macrochlamys benoiti - Ancey 1898: 128, pl. 9, fig. b. — Saurin 1953: 113. — Fischer 1973: 92. — Schileyko 2011: 30-31.

Sarika benoiti - Inkhavilay et al. 2019: 81, fig. 38c.

\section{Diagnosis}

Shell sub-depressed, medium-sized (shell width $16.0 \mathrm{~mm}$, shell height $9.0 \mathrm{~mm}$ ), rather thin, semitranslucent and brownish. Shell surface smooth and glossy; more glossy below the periphery; suture impressed; spire slightly elevated; apex rather obtuse. Entire shell consisting of 6 whorls and increasing regularly. Last whorl rounded on the periphery. Aperture obliquely oval-lunate shaped; peristome simple. Umbilicus narrowly opened and deep.

\section{Remarks}

Sarika benoiti can be found in Thailand, Laos, Vietnam and Cambodia (Ancey 1898; Fischer \& Dautzenberg 1904; Saurin 1953; Fischer 1973; Schileyko 2011; Inkhavilay et al. 2019). In Cambodia, it had been listed among the land snail fauna by Fischer $(1891,1973)$ and Fischer \& Dautzenberg (1904), but with no description or illustration. No examples of this species were found in our survey but, in keeping with earlier records, we provisionally retain this species in the Cambodian land snail fauna.

Sarika bocourti (Morelet, 1875)

Table 1; Fig. 2B

Helix bocourti Morelet, 1875: 249. Type locality: L'espèce provient de Battambang, dans le Cambodje (Battambang Province, Cambodia). Breure et al. 2018: 222-223, figs 135-136.

Nanina (Macrochlamys) aff. boucourti [sic] - Tryon 1886: 89, pl. 29, figs 43-45. Ariophanta (Xesta) bocourti - Fischer 1891: 20.

Nanina (Xesta) bocourti - Fischer \& Dautzenberg 1904: 394.

\section{Diagnosis}

Shell depressed, large (shell width up to $31.0 \mathrm{~mm}$, shell height up to $14.0 \mathrm{~mm}$ ), slightly thin, semitranslucent and pale warm brown. Shell surface smooth and glossy; more glossy below the periphery; suture impressed; spire moderately elevated. Entire shell consisting of 6-7 whorls and increasing regularly. Periphery of body whorl obtusely angulated. Aperture obliquely oval-lunate shaped; peristome simple. Columellar margin simple and slightly reflected near umbilicus. Umbilicus narrowly opened and deep. 


\section{Material examined}

\section{Syntypes}

CAMBODIA • 2 shells; Battambang Province; NHMUK 1893.2.4.1076-1077.

\section{Other material}

CAMBODIA 13 shells; Battambang Province, Banan District, Phnom Sampov, Samov Mountain, locality code $\mathrm{C} 072 ; 13^{\circ} 01^{\prime} 33.60^{\prime \prime} \mathrm{N}, 103^{\circ} 06^{\prime} 03.64^{\prime \prime}$ E; CUMZ 7900.

\section{Remarks}

The distribution of $S$. bocourti is currently known only from the type locality in Battambang, Cambodia (Fig. 1). In this survey, no living specimens have been collected from the type locality.

Sarika bocourti differs from S. resplendens (specimen NHMUK 1903.7.1.112 from Cambodia) with the last whorl obtusely angulated on the periphery, while the shell in $S$. resplendens has a rounded periphery.

Sarika lactoconcha Pholyotha \& Panha sp. nov. urn:1sid:zoobank.org:act:0E48F6FB-6775-4470-BF85-345C3D43112A

Table 1; Figs 2C-D, 3

\section{Diagnosis}

Sarika lactoconcha sp. nov. is characterized by a large, depressed and whitish shell, rounded on the periphery. Animal with dark grey body and five mantle lobes. Genitalia with rather long epiphallic caecum and triangular prism-shaped penial pilasters on inner penial sculpture.

\section{Etymology}

The specific epithet 'lactoconcha' is derived from the Latin word 'lactis' meaning 'milk, milky' and the Latin word 'concha' meaning 'snail' or 'shell'. It refers to the milky colour of the shell.

\section{Material examined}

\section{Holotype}

CAMBODIA - 1 shell (width $23.6 \mathrm{~mm}$, height $12.1 \mathrm{~mm}$ ); Kampot Province, Tuek Chhou District, limestone outcrops at Phnom Chhngok Cave Temple, locality code C046; 10³8'33.8" N, 104 ${ }^{\circ} 16^{\prime} 08.3^{\prime \prime}$ E; CUMZ 7901.

\section{Paratypes}

CAMBODIA 11 shell, 3 alcohol-preserved specimens; same collection data as for holotype; CUMZ 7902 - 1 shell; same collection data as for preceding; NHM $\bullet 1$ shell; same collection data as for preceding; ZRC.

\section{Other material}

CAMBODIA - 2 shells; Kampot Province, Tuek Chhou District, limestone outcrops at Phnom Kbal Romeas, locality code C045; 10³6'59.6" N, 104¹4'37.8” E; CUMZ 7903.

\section{Description}

Shell (Fig. 2C-D). Depressed, large (shell width up to $23.7 \mathrm{~mm}$, shell height up to $12.1 \mathrm{~mm}$ ), rather thin, semitransparent. Shell surface generally smooth, glossy; more glossy below periphery; shell colour monochrome pale milky or whitish colour. 6-61/2 whorls, increasing regularly, slightly convex, separated by rather shallow and wide suture. Spire slightly elevated; last whorl broadly rounded. Aperture oval- 


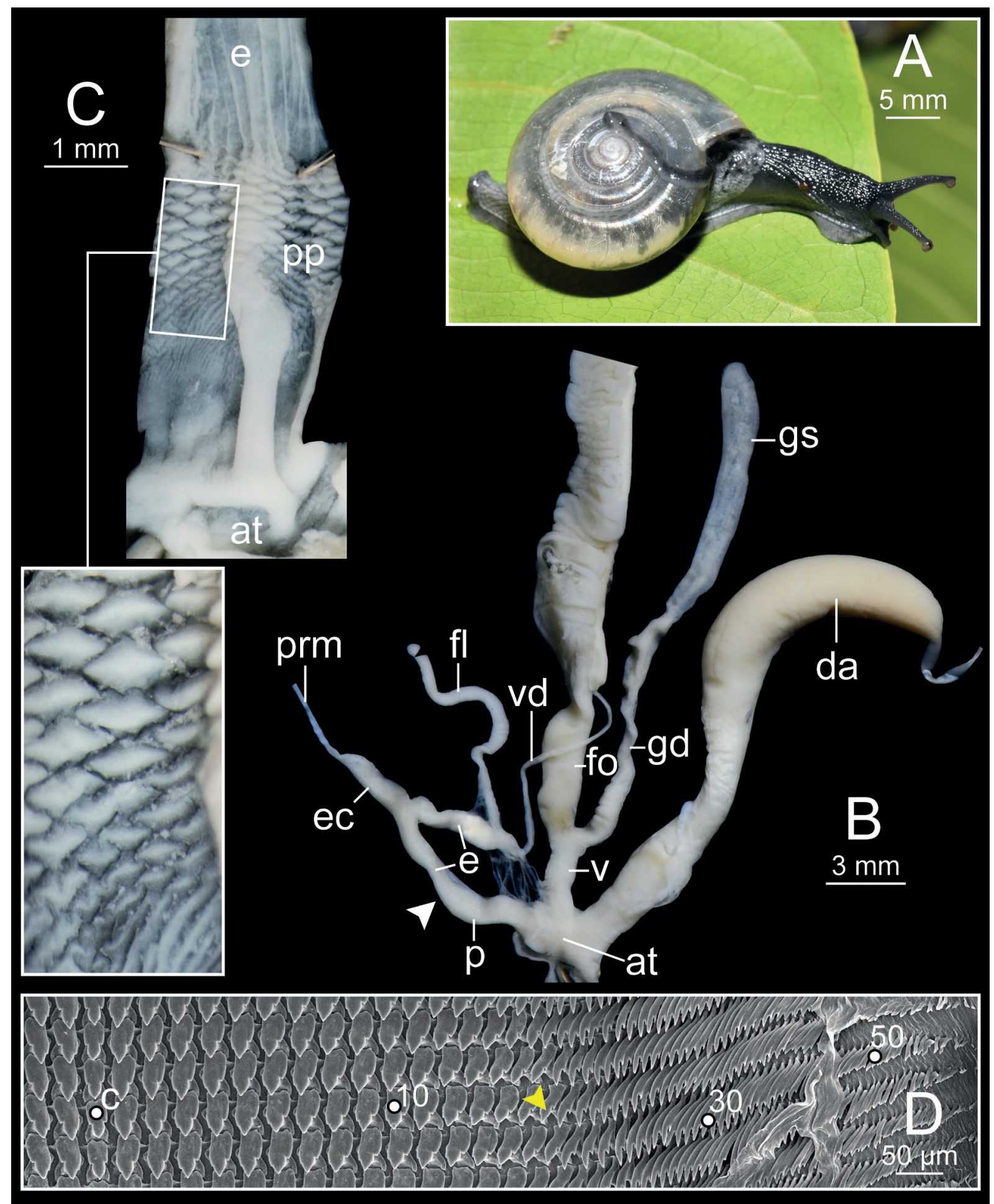

Fig. 3. Sarika lactoconcha Pholyotha \& Panha sp. nov., paratype (CUMZ 7902). A. Living snail. B. General view of genital system. C. Internal structure of penis. D. Representative SEM image of the radula. Central tooth indicated by ' $\mathrm{C}$ '; yellow arrow heads indicate lateral teeth with the transition to marginal teeth; white arrow heads indicate the end of penis. 
lunate shaped, open obliquely. Peristome simple, very slightly thickened, not expanded. Parietal callus thin, transparent; columellar margin simple, slightly reflected near umbilicus. Umbilicus narrow, deep.

EXTERNAL FEATURES (Fig. 3A). Living animals have dark grey body; dorsally with darker colour than below, foot sole. Caudal foss present; caudal horn raised, rather large. Mantle and lung scattered with dark pigment or spots or blotches. Mantle edge well-developed, dark grey to paler in colour, with three dorsal lobes, two shell lobes (see Pholyotha et al. 2018: fig. 1). Dorsal lobes large, broad; right dorsal lobe larger than both anterior and posterior left dorsal lobes. Shell lobes large, long; right shell lobe larger, longer than left shell lobe.

Genitalia (Fig. 3B-C). Atrium (at) enlarged, very short. Penis (p) cylindrical, with thin penial sheath covering proximal penis. Inner sculpture of penis very finely folded to nearly smooth surface close to atrium then gradually transforming to triangular prism (rhombic base, acute angle on top) penial pilaster (pp) near epiphallus. Epiphallus (e) cylindrical, elongate, about two times penis length. Epiphallic caecum (ec) similar diameter as epiphallus, straight, located near middle of epiphallus. Penial retractor muscle (prm) thin, attached at tip of epiphallic caecum. Flagellum (fl) slender, rather long, nearly 1.5 times epiphallus length. Vas deferens (vd) thin tube. Vagina (v) cylindrical, about half of penis length. Dart apparatus (da) cylindrical, rather large and long, joined to atrium at vagina and penis junction. Gametolytic sac (gs) elongate bulbous; gametolytic duct (gd) enlarged cylindrical. Free oviduct (fo) enlarged cylindrical, approximately two times vagina length, proximally encircled with brownish tissue. Oviduct large lobules; prostate gland running alongside oviduct.

RAdULA (Fig. 3D). Teeth arranged in wide-angle U-shape with half row formula: 1-(15-16)-65 teeth. Central tooth symmetrical tricuspid with pointed cusps; mesocone large lanceolate, dull cusp; ectocones very small. Lateral teeth asymmetrical tricuspid; mesocone large with pointed cusp; endocone very small, located near tip; ectocone larger than endocone, located in middle of tooth. Marginal teeth starting around tooth numbers 15-16, obliquely bicuspid; endocone large, pointed cusp; ectocone small. Outermost teeth gradually reduced in size from elongate, narrow teeth to very short teeth.

\section{Distribution}

This new species is currently known from Phnom Chhngok Cave (the type locality), an undisturbed small karst outcrop, which is about $1 \mathrm{~km}$ long and surrounded by rice fields. Another locality is Phnom Kbal Romeas, a small limestone outcrop. This outcrop (Fig. 1) is situated about $4 \mathrm{~km}$ southwest of the type locality, surrounded by housing areas and an inactive old quarry, and now has become a tourist attraction.

\section{Remarks}

Sarika lactoconcha sp. nov. differs from S. benoiti, S. bocourti and S. resplendens with whitish shell, while the three latter species have brownish shells. Moreover, S. lactoconcha sp. nov. has a rounded last whorl, while $S$. bocourti has an obtusely angulated last whorl. Unfortunately, no genital information of $S$. resplendens from Cambodia is available for further comparison. However, the genitalia of S. resplendens from Myanmar possess a large penial retractor muscle with about the same diameter as the epiphallic caecum, and short flagellum compared with penis (see Godwin-Austen 1907: 179-181, pl. 111, figs 3, 3a for comparison), while this new species has a small and thin penial retractor muscle and long flagellum.

Compared to species of Sarika-Macrochlamys having a whitish shell, S. lactoconcha sp. nov. has a wider last whorl (loosely coiled), apertural lip simple and genitalia without penial verge. Meanwhile, S. consepta (Benson, 1860) from Myanmar has a narrow last whorl (densely coiled), apertural lip slightly expanded and rather thickened inside, and genitalia with large penial verge (see Pholyotha et al. 2020 
for comparison). Another species, Macrochlamys psyche Vermeulen et al., 2019 was recently described from southern Vietnam. This Macrochlamys species has a flattened to slightly concaved spire, whereas S. lactoconcha sp. nov. has an elevated spire. Unfortunately, the genital anatomy of $M$. psyche is not available for comparison, therefore, its generic placement is still provisional.

Sarika khmeriana Pholyotha \& Panha sp. nov. urn:lsid:zoobank.org:act:13BEB7E0-40BD-480C-ABA7-72798C9E6AF2

Table 1; Figs 4A-B, 5, 6A-F

\section{Diagnosis}

Sarika khmeriana sp. nov. can be characterized by a large, depressed shell, rounded on the periphery. Shell colour dark brownish and usually with pale brownish (to whitish) umbilical area. Animal has dark grey body and left shell lobe is absent. Genitalia have rather long epiphallic caecum and inner wall of penis sculptured with triangular prism penial pilasters. Spermatophore head filament with irregularly serrated longitudinal folds; tail filament bearing two spines near sperm sac and branching spines along the entire tail filament length.

\section{Etymology}

The specific epithet 'khmeriana' refers to the Khmer Empire, of which Cambodia is the residual state.

\section{Material examined}

\section{Holotype}

CAMBODIA • 1 shell (width $24.2 \mathrm{~mm}$, height $12.3 \mathrm{~mm}$ ); Kampot Province, Dang Tong District, limestone outcrops near Totong Temple, locality code C041; 1041'59.8" N, 104³1'30.1" E; CUMZ 7904.

\section{Paratypes}

CAMBODIA - 6 shells, 11 alcohol-preserved specimens; same collection data as for holotype; CUMZ $7905 \cdot 2$ shells; same collection data as for preceding; NHMUK $\bullet 2$ shells; same collection data as for preceding; ZRC.

\section{Other material}

CAMBODIA -24 shells, 17 alcohol-preserved specimens; Kampot Province, Banteay Meas District, limestone outcrops at Prasat Phnom Totong Temple, locality code C042; 1041'47.9" N, 104'31'25.5" E; CUMZ 7906.

\section{Description}

Shell (Fig. 4A-B). Depressed, large (shell width up to $24.2 \mathrm{~mm}$, shell height up to $12.3 \mathrm{~mm}$ ), rather thin, semi-translucent. Shell colour dark brownish on upper surface and at periphery; below periphery surrounding umbilicus pale to very pale brownish. Shell surface smooth, glossy; more glossy below periphery; suture rather shallow with narrow, whitish subsutural band. Spire slightly elevated; whorls $6-61 / 2$, increasing regularly; last whorl broadly rounded on periphery. Aperture obliquely crescentshaped; peristome simple. Columellar margin simple, slightly reflected near umbilicus. Umbilicus somewhat narrow and deep.

EXTERNAL FEATURES (Fig. 5A). Living animals have monochrome dark grey body with pale grey foot sole. Caudal foss present; caudal horn elevated and large. Mantle edge well developed with three dorsal lobes and one shell lobe (see Pholyotha et al. 2018: fig. 1). Shape and size of dorsal lobes and right shell lobe (left shell lobe absent) similar to previous species. 
Genitalia (Fig. 5B-C). Atrium (at) enlarged, very short. Penis (p) cylindrical, with thin penial sheath covering proximal penis. Inner sculpture of penis very finely folded to nearly smooth then gradually transformed to triangular prism (rhombic base and acute angle on top) penial pilasters (pp) near epiphallus. Epiphallus (e) cylindrical, elongate, about two times penis length. Epiphallic caecum (ec)

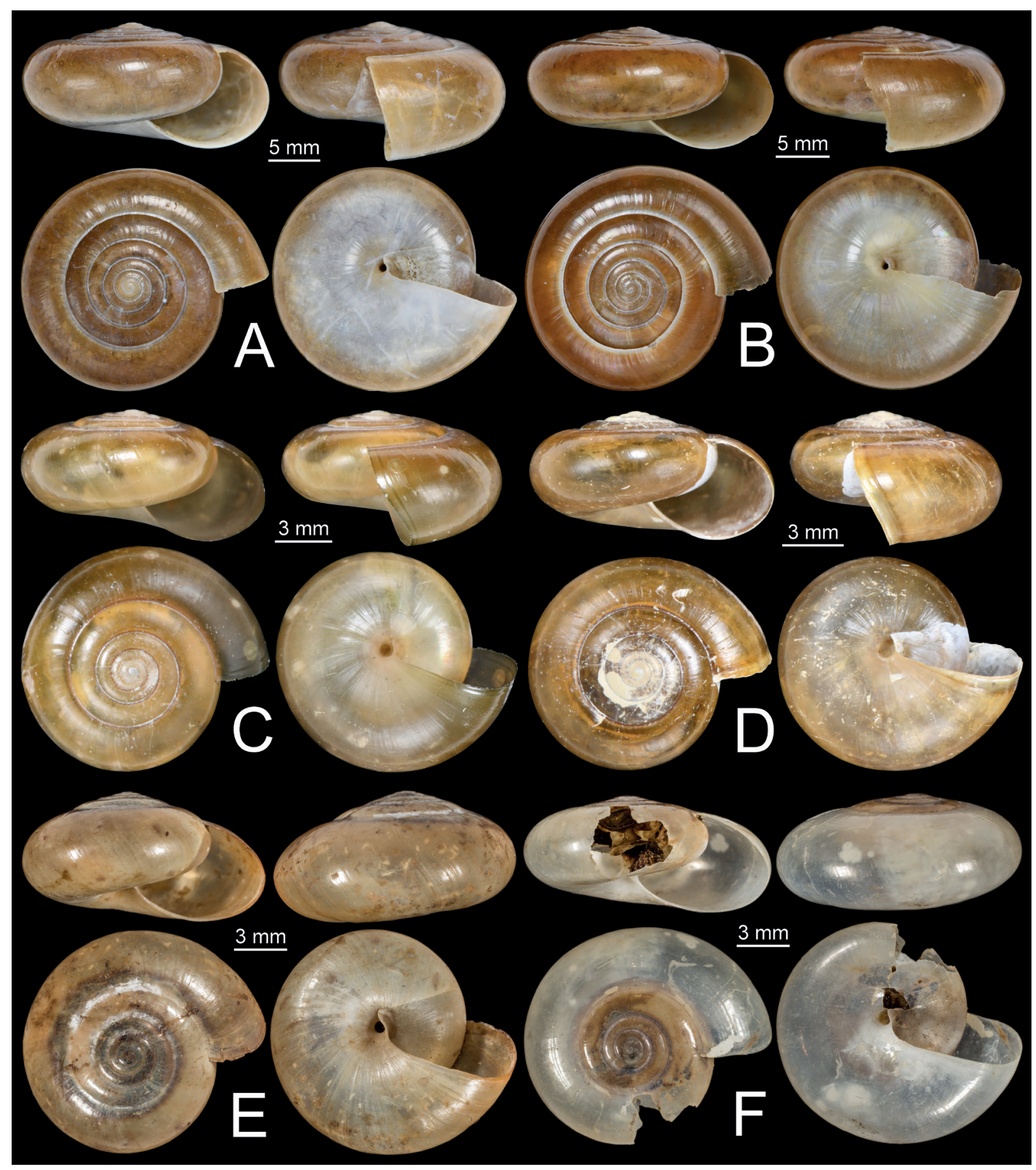

Fig. 4. Shells of Sarika spp. A. Sarika khmeriana Pholyotha \& Panha sp. nov., holotype (CUMZ 7904). B. Sarika khmeriana Pholyotha \& Panha sp. nov., paratype (CUMZ 7905). C. S. nana Pholyotha \& Panha sp. nov., holotype (CUMZ 7907). D. S. nana Pholyotha \& Panha sp. nov., paratype (CUMZ 7908). E. Macrochlamys excepta (Mabille, 1887), syntype (MNHN-IM-2000-27886). F. M. zero (Mabille, 1887), syntype (MNHN-IM-2000-27782). 
large, similar diameter as penis, straight and located near middle of epiphallus. Penial retractor muscle (prm) thin, attached at tip of epiphallic caecum. Flagellum (fl) slender, somewhat long, about 1.5 times epiphallus length. Vas deferens (vd) a thin tube. Vagina (v) cylindrical, similar length as penis. Dart apparatus (da) cylindrical, rather large, long, attached to atrium at penis and vagina junction. Gametolytic sac (gs) enlarged, bulbous (spermatophore inside); gametolytic duct (gd) long, cylindrical. Free oviduct

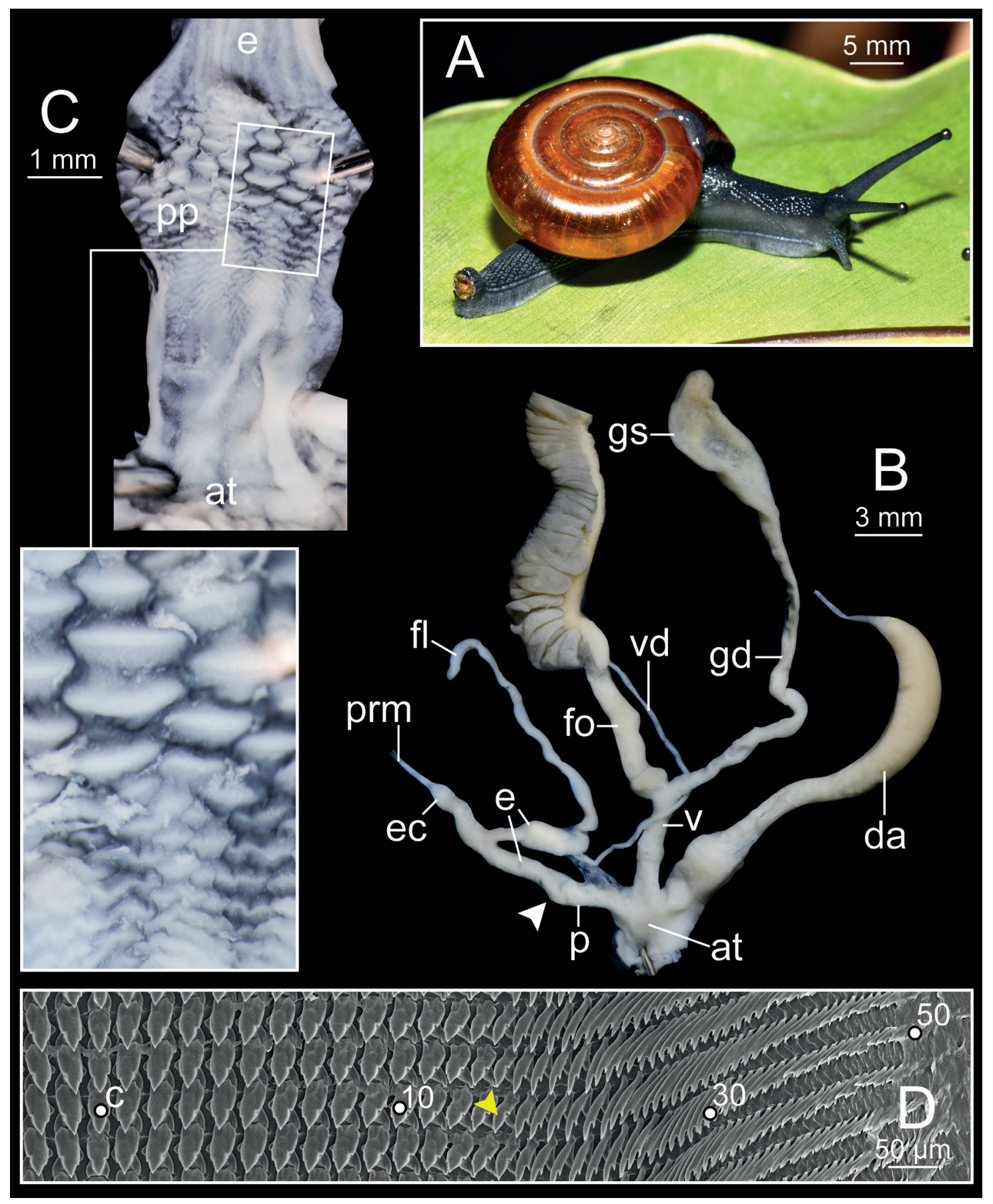

Fig. 5. Sarika khmeriana Pholyotha \& Panha sp. nov., paratype (CUMZ 7905). A. Living snail. B. Beneral view of genital system. C. Internal structure of penis. D. Representative SEM image of the radula. Central tooth indicated by ' $\mathrm{C}$ '; yellow arrow heads indicate lateral teeth with the transition to marginal teeth; white arrow heads indicate the end of penis. 
(fo) cylindrical, longer than vagina, proximal end encircled with thickened tissue. Oviduct large lobules; prostate gland running alongside oviduct.

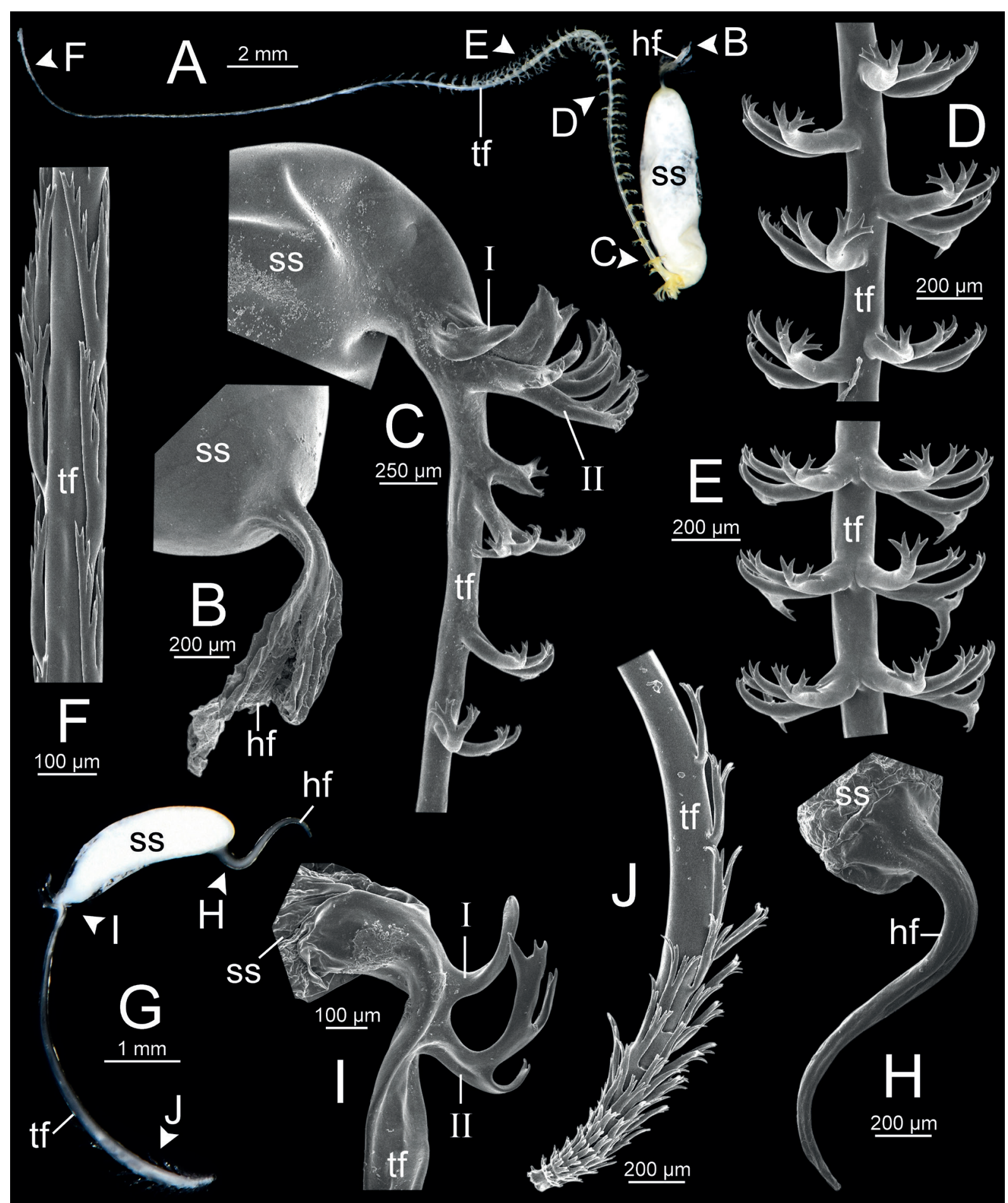

Fig. 6. SEM images of spermatophores. A-F. Sarika khmeriana Pholyotha \& Panha sp. nov., paratype (CUMZ 7905). A. General view of spermatophore. B. Head filament. C-F. Detail of tail filament. G-J. S. nana Pholyotha \& Panha sp. nov., paratype (CUMZ 7908). G. General view of spermatophore. H. Head filament. I-J. Detail of tail filament. 
Spermatophore (Fig. 6A-F). Sperm sac (ss) enlarged, elongate-oval. Head filament (hf) enlarged (most was missing) with irregularly serrated longitudinal folds. Tail filament (tf) very long tube, region close to sperm sac bearing two spines. Spine I simple, short; spine II with complicated branching into small, numerous spinules. Spines on tail filament starting just after spine II, with complicated branching into spinules, arranged alternate (Fig. 7D) or opposite (Fig. 7F).

RAdULA (Fig. 5D). Teeth arranged in wide-angle U-shape with half row formula: 1-(13-14)-55 teeth. Central tooth symmetrical tricuspid with triangular-shaped mesocone; ectocones very small. Lateral teeth asymmetrical tricuspid; mesocone large, pointed cusp; endocone small, located near the tip; ectocone larger than endocone, pointed cusp, located in middle of tooth. Marginal teeth occurring around tooth numbers 13-14, obliquely bicuspid; endocone elongate, pointed cusp; ectocone small, pointed cusp. Outermost teeth gradually reduced in size as cusps to small teeth.

\title{
Distribution
}

This new species is known from two locations very close to each other, on limestone outcrops. Totong Mountain (type locality) is a small karst with an old quarry, surrounded by housing areas and is adjacent to paddy fields (Fig. 1). The second locality, Prasat Phnom Totong, about $500 \mathrm{~m}$ south of the type locality, is a very large and active mining site of a cement factory.

\section{Remarks}

Sarika khmeriana sp. nov. is quite similar in terms of shell shape with $S$. lactoconcha sp. nov., but this species is distinct in possessing dark brown shell on upper surface and pale brownish (to whitish) surrounding umbilicus, and left shell lobe absent (four mantle lobes); whereas S. lactoconcha sp. nov. has a monochrome pale milky shell, and well-developed left shell lobe (five mantle lobes).

This new species differs from $S$. resplendens in having a thin penial retractor muscle and the entire tail filament of spermatophore has branching spines, whereas the genitalia of $S$. resplendens (see Godwin-Austen 1907: fig. 3) have a large and thickened penial retractor muscle, and the tail filament of spermatophore is without a branching spine. Compared with other species of Sarika from Cambodia, $S$. khmeriana sp. nov. is rounded on the periphery while $S$. bocourti is obtusely angulated on the periphery, and this new species has a larger shell diameter than $S$. benoiti. Sarika khmeriana sp. nov. also differs from $M$. despecta (Mabille, 1887) from northern Vietnam in having an elevated spire and narrower umbilical opening.

\author{
Sarika nana Pholyotha \& Panha sp. nov. \\ urn:lsid:zoobank.org:act:48DF9AB1-369C-4930-A006-9E57AE9DBACB \\ Table 1; Figs 4C-D, 6G-J, 7
}

\section{Diagnosis}

Sarika nana sp. nov. can be characterized by medium shell size, globosely depressed, pale yellowishbrown shell, and well-rounded periphery. Animal has dark grey body and five mantle lobes. Genitalia have a rather long epiphallic caecum, short penial caecum, rather large penial verge and oval-shaped penial pilasters. Spermatophore has smooth head filament and tail filament near sperm sac bearing two spines, and terminal one-third of tail filament contains a series of short branching spines.

\section{Etymology}

The specific epithet 'nana' is from the Latin word 'nanus' meaning "dwarf" and refers to the small-sized species in this genus. 


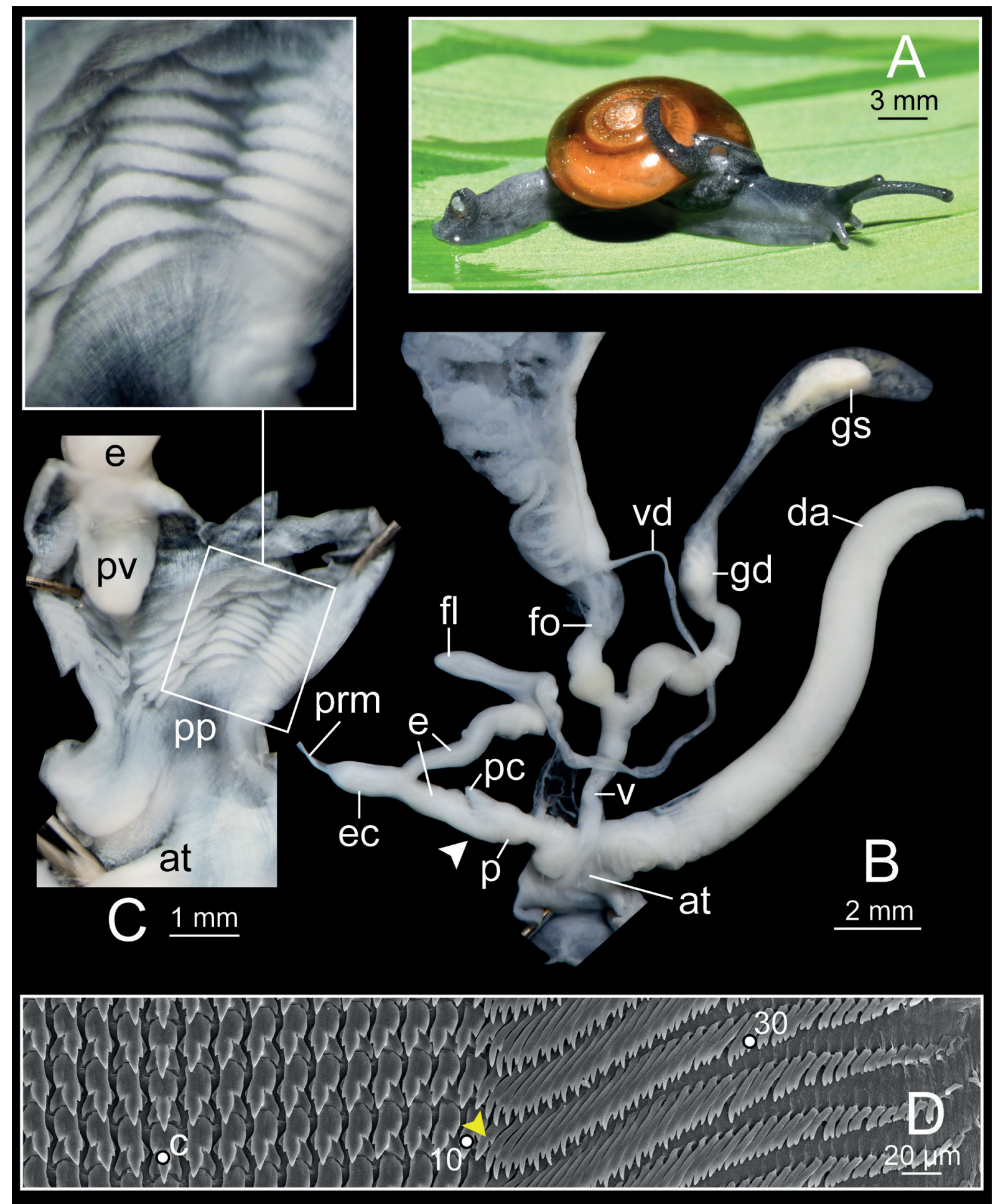

Fig. 7. Sarika nana Pholyotha \& Panha sp. nov., paratype (CUMZ 7908). A. Living snail. B. General view of genital system. C. Internal structure of penis. D. Representative SEM image of the radula. Central tooth indicated by ' $\mathrm{C}$ '; yellow arrow heads indicate lateral teeth with the transition to marginal teeth; white arrow heads indicate the end of penis. 


\section{Material examined}

Holotype

CAMBODIA - 1 shell (width $12.6 \mathrm{~mm}$, height $6.8 \mathrm{~mm}$ ); Takeo Province, Kiri Vong District, the conglomerate hills at Phnom Bayang Temple, locality code C036; $10^{\circ} 38^{\prime} 28.2^{\prime \prime} \mathrm{N}, 104^{\circ} 50^{\prime} 35.8^{\prime \prime} \mathrm{E}$; CUMZ 7907.

\section{Paratypes}

CAMBODIA $\bullet 24$ alcohol-preserved specimens; same collection data as for holotype; CUMZ $7908 \cdot 2$ shells; same collection data as for preceding; NHMUK $\bullet 2$ shells; same collection data as for preceding; ZRC.

\section{Description}

SheLl (Fig. 4C-D). Globosely depressed, medium-sized (shell width up to $12.3 \mathrm{~mm}$, shell height up to $6.8 \mathrm{~mm}$ ), thin, rather translucent. Shell surface smooth, shiny; more shiny below periphery; shell colour pale yellowish brown. Entire shell consisting of 51/2-6 whorls increasing regularly, separated by shallow suture. Spire slightly elevated; last whorl broad, well-rounded. Aperture obliquely oval-lunate shaped. Peristome simple. Columellar margin simple, slightly expanded near umbilicus. Umbilicus opened, wide, deep.

EXTERNAL FEATURES (Fig. 7A). Living animals having monochrome pale grey body, foot sole. Caudal foss, large caudal horn present. Mantle edge well developed, dark colour, with three dorsal lobes and two shell lobes (see Pholyotha et al. 2018: fig. 1). Dorsal lobes and shell lobes similar to those of S. lactoconcha sp. nov.

Genitalia (Fig. 7B-C). Atrium (at) very short. Penis (p) short, cylindrical with thin penial sheath covering proximal penis. Distal penis slightly enlarged with penial caecum (pc), corresponding to penial verge. Inner sculpture of penis proximally with smooth surface then transformed to thickened, corrugated transverse-folded penial pilasters (pp) surrounding penial verge near distal end. Penial verge (pv) large with blunt tip. Epiphallus (e) cylindrical, about twice penis length. Epiphallic caecum (ec) similar diameter as epiphallus, straight, located near proximal epiphallus. Penial retractor muscle (prm) thin, attached at tip of epiphallus. Flagellum (fl) slender, short, about half the length of epiphallus. Vas deferens (vd) thin tube. Vagina (v) cylindrical, little longer than penis. Dart apparatus (da) cylindrical, rather large and long, connected to atrium at vagina and penis junction. Gametolytic sac (gs) enlarged, bulbous (spermatophore inside); gametolytic duct (gd) cylindrical, long. Free oviduct (fo) cylindrical, same length as vagina, proximal end encircled with thickened, brownish tissue. Oviduct enlarged lobules; prostate gland running alongside oviduct.

Spermatophore (Fig. 6G-J). Sperm sac (ss) enlarged, elongate-oval. Head filament (hf) located subapical of sperm sac, with long, smooth surface. Tail filament (tf) about two times longer than sperm sac, region close to sperm sac bearing two spines. Spine I simple, curved, with dull tip. Spine II large, branching into spinules (antler like). Region furthest away smooth, without spine; terminal part (about one-fourth of its length) consisting of short to long branching spines arranged in row or encircling tip.

RADULA (Fig. 7D). Teeth arranged in wide-angle U-shape with half row formula: 1-(10-11)-46 teeth. Central tooth symmetrical tricuspid; mesocone large, lanceolate shape; ectocones small with triangular shape. Lateral teeth asymmetrical tricuspid with large, pointed cusp mesocone; endocone small, pointed cusp, located near tip; ectocone rather large, triangular-shaped, located in middle of tooth. Marginal teeth starting around tooth numbers 10-11, obliquely bicuspid; endocone elongate, pointed cusp; ectocone small, pointed cusp. Outermost teeth gradually smaller in size from lateral teeth to edge. 


\section{Distribution}

This new species is known only from the conglomerate mountain Phnom Bayang (type locality; Fig. 1). The habitat at the collection site is an evergreen forest mixed with fruit orchards and with outcroppings of large granite boulders. This location is surrounded by villages and is adjacent to paddy fields.

\section{Remarks}

Sarika nana sp. nov., a medium-sized species, can be distinguished from all species of Sarika recorded from mainland Indochina by having a penial verge. Compared to medium-sized species of Macrochlamys, body whorl of $S$. nana sp. nov. is relatively broader and more well-rounded on the periphery, umbilicus is relatively wider and aperture opening is less convex than M. excepta (Mabille, 1887) (Fig. 4E) and M. zero (Mabille, 1887) (Fig. 4F). The type locality of the new species is about $1000 \mathrm{~km}$ from the two species described from Northern Vietnam. The Thai species M. brunnea Möllendorff, 1902 has much narrower umbilical opening than this new species (see Pholyotha et al. 2018: fig. 8a). Unfortunately, the anatomical data of M. brunnea, M. excepta and M. zero is unavailable for further comparison.

\section{Discussion}

Cambodian terrestrial gastropods are poorly known with most literature dating from the late $18^{\text {th }}$ to the early $20^{\text {th }}$ century. New land snail species, mostly Ariophantidae but excluding Sarika, have recently been published from Vietnam and Cambodia (Vermeulen et al. 2007, 2019). The three species of Sarika recorded from Cambodia have remained unchanged for more than a century (Crosse \& Fischer 1863; Fischer 1891; Fischer \& Dautzenberg 1904). The three new species discovered in this study, S. lactoconcha sp. nov., S. khmeriana sp. nov. and S. nana sp. nov. are the first land snails in the genus Sarika to be described from Cambodia in almost 145 years.

Interestingly, all new species had a high degree of endemism and were found in association with karst formations and mountainous areas on the west flank of the Mekong River delta in Cambodia. The vast alluvial plain of the Mekong delta area from Cambodia to Vietnam has a group of several scattered limestone outcrops and hosts an exclusive concentration of endemic taxa including snails (Vermeulen et al. 2019), insects (Bayarsaikhan et al. 2019) and geckos (Nguyen et al. 2018). Indeed, the Mekong delta limestone hills are recognized as possessing habitat island faunas with relatively few species but high rates of endemism. Study of the Cambodian land snail fauna is in its infancy (Vermeulen et al. 2007, 2019).

Land snails of the genus Macrochlamys sensu stricto were not found in Cambodia during our field collections. The distribution ranges and records of the genus in Cambodia are still questionable, in contrast to Thailand and Myanmar, where many species of Macrochlamys were recently reported (Pholyotha et al. 2018, 2020). Although the reproductive anatomy of M. psyche has not yet been examined, it was recently described from southern Vietnam (Vermeulen et al. 2019). So far, most of the species of Sarika-Macrochlamys in Indochina, especially Cambodia, Laos and Vietnam have only been described based on shell characters, and the investigation of genitalia is still sorely needed. In addition to the need for anatomical descriptions, the systematics of the group of Macrochlamys/Sarika can only be resolved by a species diverse molecular phylogeny.

\section{Acknowledgements}

The authors would like to thank K. Pin (Fisheries Administration, Cambodia), T.H. Ng (NUS, Singapore), E. Jeratthitikul and W. Siriwut (Mahidol University), and R. Srisonchai (Khon Kaen University) for their kind help during field trips in Cambodia. The authors are also indebted to J. Ablett, F. Naggs and H. Taylor (NHM, London), P. Bouchet, V. Héros, D. Brabant and M. Caballer (project E-RECOLNAT: ANR-11-INBS-0004, MNHN, Paris) for allowing the authors to examine the material housed in the type 
collections, the type material database and photographs. Special thanks go to the Inland Fisheries Research and Development Institute (IFReDI) of the Cambodia Fisheries Administration for the preparation of permission documents and data collection in Cambodia. The work was funded by TRF Strategic Basic Research DBG 6080011 (2017-2019), The Thailand Research Fund (TRF-DPG628001), and Center of Excellence on Biodiversity (BDC-PG2-160012). Additionally, this project was supported by a grant from the Human Resource Development in Science Project (Science Achievement Scholarship of Thailand) to AP. We thank Thor-Seng Liew and Fred Naggs for useful comments which improved this paper.

\section{References}

American Veterinary Medical Association 2020. AVMA Guidelines for the Euthanasia of Animals: 2020 Edition. Available from https://www.avma.org/sites/default/files/2020-01/2020-Euthanasia-Final-1-17-20.pdf [accessed 12 Feb 2020].

Ancey C.F. 1898. Notes malacologiques. B - Descriptions d'espèces nouvelles du centre de l'Afrique. Annales du Musée d'Histoire Naturelle de Marseille, Série II 1 (1): 125-150.

Bayarsaikhan U., Ko J.H. \& Bae Y.S. 2019. A new species of the genus Eugoa Walker, 1858 (Lepidoptera, Erebidae, Arctiinae) from Cambodia. Zootaxa 4543: 414-420. https://doi.org/10.11646/zootaxa.4543.3.6

Blanford W.T. \& Godwin-Austen H.H. 1908. Mollusca: Testacellidae and Zonitidae. In: Bingham CT (ed.) The Fauna of British India including Ceylon and Burma. Taylor and Francis, London.

Breure A.S.H., Audibert C. \& Ablett J.D. 2018. Pierre Marie Arthur Morelet (1809-1892) and his contributions to malacology. Nederlandse Malacologische Vereniging, Leiden.

Collinge W.E. 1903. Report on the non-operculate land Mollusca. Fasciculi Malayenses: Zoology 2: 205-218.

Crosse H. \& Fischer P. 1863. Note sur la faune malacologique de Cochinchine, comprenant la description des espèces nouvelles ou peu connues. Journal de Conchyliologie 11: 343-379.

Fischer H. \& Dautzenberg P. 1904. Catalogue des mollusques terrestres et fluviatiles de l'Indo-Chine orientale cités jusqu'à ce jour. In:-Mission Pavie, Etudes diverses 3: 390-450.

Fischer P. 1891. Catalogue et distribution géographique des Mollusques terrestres, fluviatilies \& marins d'une partie de l'Indo-Chine (Siam, Laos, Cambodge, Cochinchine, Annam, Tonkin). Imprimerie Dejussieu Père et Fils, Autun. https://doi.org/10.5962/bhl.title.14809

Fischer P.H. 1973. Les mollusques testacés du Cambodge. Seconde partie: Gastéropodes Pulmonés, Bivalves et bibliographie. Journal de Conchyliologie 90: 89-113.

Godwin-Austen H.H. 1883-1907. Land and Freshwater Mollusca of India, including South Arabia, Baluchistan, Afghanistan, Kashmir, Nepal, Burmah, Pegu, Tenasserim, Malay Peninsula, Ceylon, and other Islands of the Indian Ocean. Supplementary to Messrs. Theobald and Hanley's Conchologia Indica. Taylor and Francis, London. https://doi.org/10.5962/bhl.title.18138

Hanley S. \& Theobald W. 1872 [1870-1876]. Conchologica Indica: Illustrations of the Land and Freshwater Shells of British India. L. Reeve \& Co, London.

Hemmen J. \& Hemmen C. 2001. Aktualisierte Liste der terrestrischen Gastropoden Thailands. Schriften zur Malakozoologie aus dem Haus der Natur-Cismar 18: 35-70.

Hyman I.T. \& Ponder W.F. 2010. A morphological phylogenetic analysis and generic revision of Australian Helicarionidae (Gastropoda: Pulmonata: Stylommatophora), and an assessment of the relationships of the family. Zootaxa 2462: 1-148. https://doi.org/10.11646/zootaxa.2462.1.1 
Hyman I.T. \& Ponder W.F. 2016. Helicarionidae (Gastropoda: Heterobranchia: Stylommatophora) of Lord Howe Island. Molluscan Research 36: 84-107. https://doi.org/10.1080/13235818.2015.1128568

Inkhavilay K., Sutcharit C., Bantaowong U., Chanabun R., Siriwut W., Srisonchai R., Pholyotha A., Jirapatrasilp P. \& Panha S. 2019. Annotated checklist of the terrestrial molluscs from Laos (Mollusca, Gastropoda). ZooKeys 834: 1-166. https://doi.org/10.3897/zookeys.834.28800

Laidlaw F.F. 1933. A list of the land and fresh-water Mollusca of the Malay peninsula. Journal of the Malaysian Branch of the Royal Asiatic Society 11: 211-234.

Liew T.S., Schilthuizen M. \& Vermeulen J.J. 2009. Systematic revision of the genus Everettia GodwinAusten, 1891 (Mollusca: Gastropoda: Dyakiidae) in Sabah, northern Borneo. Zoological Journal of the Linnean Society 157: 515-550. https://doi.org/10.1111/j.1096-3642.2009.00526.x

Maassen W.J.M. 2001. A preliminary checklist of the non-marine molluscs of West-Malaysia. "A Handlist”. De Kreukel, Extra Editie 2001: 1-155.

Maneevong A. 2000. Taxonomic revision of terrestrial snails genera Macrochlamys, Cryptozona and Hemiplecta in Thailand. Master Thesis. Department of Biology, Faculty of Science, Chulalongkorn University, Bangkok.

Morelet A. 1875. Séries Conchyliologiques comprenant l'Énumération de Mollusques terrestres et fuviatiles recueillies pendant le Cours de différents Voyages ainsi que la Description de plusieurs Espèces nouvelles. Quatrième livraison: 227-377. Paris.

Nguyen H.N., Lu C.W., Chu J.H., Grismer L.L., Hung C.M. \& Lin S.M. 2018. Historical demography of four gecko species specializing in boulder cave habitat: Implications in the evolutionary dead end hypothesis and conservation. Molecular Ecology 28:772-784. https://doi.org/10.1111/mec.14985

Panha S. 1996. A checklist and classification of the terrestrial pulmonate snails of Thailand. Walkerana 8: $31-40$.

Panha S. 1997. Taxonomy and karyotypes of land pulmonate snails of Thailand. Research report (Project: RSA/15/1994). Department of Biology, Faculty of Science, Chulalongkorn University, Bangkok.

Pfeiffer L. 1848. Monographia heliceorum viventium: sistens descriptiones systematicas et criticas omnium hujus familiae generum et specierum hodie cognitarum, volume primum. Lipsiae: F.A. Brockhaus. https://doi.org/10.5962/bhl.title.124010

Pfeiffer L. 1849 [1841-1850]. Die Schnirkelschnecken nebst den zunächst verwandten Gattungen. Dritter Theil. Systematisches Conchylien-Cabinet von Martini und Chemnitz. [Published in parts, dates follow Welter-Schultes (1999)].

Pfeiffer L. 1868. Monographia heliceorum viventium supplementum tertium: sistens descriptiones systematicas et criticas omnium hujus familiae generum et specierum hodie cognitarum, volume quintum. Lipsiae: F.A. Brockhaus.

Philippi R.A. 1846. Vier neue Konchylienarten. Zeitschrift für Malakozoologie 3: 191-192.

Pholyotha A., Sutcharit C. \& Panha S. 2018. The land snail genus Macrochlamys Gray, 1847 from Thailand, with descriptions of five new species (Pulmonata: Ariophantidae). Raffles Bulletin of Zoology 66: 763-781.

Pholyotha A., Sutcharit C., Tongkerd P., Lin A. \& Panha S. 2020. Taxonomic revision of the land snail genera Macrochlamys Gray, 1847 and Sarika Godwin-Austen, 1907 (Eupulmonata: Ariophantidae) from Southeastern Myanmar, with descriptions of three new species. Molluscan Research 40: 183-204. https://doi.org/10.1080/13235818.2020.1723041

Saurin E. 1953. Coquilles nouvelles de l'Indochine. Journal de Conchyliologie 93: 113-120. 
Schileyko A.A. 2002. Treatise on recent terrestrial pulmonate molluscs. Part 9. Helicarionidae, Gymnarionidae, Rhysotinidae, Ariophantidae. Ruthenica, Supplement 2: 1167-1307.

Schileyko A.A. 2003. Treatise on recent terrestrial pulmonate molluscs. Part 10. Ariophantidae, Ostracolethidae, Ryssotidae, Milacidae, Dyakiidae, Staffordiidae, Gastrodontidae, Zonitidae, Daudebardiidae, Parmacellidae. Ruthenica, Supplement 2: 1309-1466.

Schileyko A.A. 2011. Check-list of land pulmonate molluscs of Vietnam (Gastropoda: Stylommatophora). Ruthenica 21: 1-68.

Solem A. 1966. Some non-marine mollusks from Thailand, with notes on classification of the Helicarionidae. Spolia Zoologica Musei Hauniensis 24: 1-110.

Sutcharit C. \& Panha S. 2008. Taxonomic re-evaluation of Sarika diadema (Dall, 1897) and S. asamurai (Panha, 1997), two endemic land snails from Thailand (Pulmonata: Ariophantidae: Macrochlamydinae). The Raffles Bulletin of Zoology 56: 95-100.

Tryon Jr. G.W. 1886. Manual of Conchology; Structural and Systematic. With illustrations of the species. Second Series: Pulmonata. Volume II. Zonitidae. Academy of Natural Sciences, Philadelphia.

Vermeulen J.J., Luu H.T., Theary K. \& Anker K. 2019. New species of land snails (Mollusca: Gastropoda: Caenogastropoda and Pulmonata) of the Mekong Delta Limestone Hills (Cambodia, Vietnam). Folia Malacologica 27: 7-41. https://doi.org/10.12657/folmal.027.001

Vermeulen J.J., Phung C.L. \& Truong Q.T. 2007. New species of terrestrial molluscs (Caenogastropoda, Pupinidae \& Pulmonata: Vertiginidae) of the Hon Chong - Ha Tien limestone hills, Southern Vietnam. Basteria 71: 81-92.

Welter-Schultes F.W. 1999 Systematisches Conchylien-Cabinet von Martini und Chemnitz (1837-1920), bibliography of the volumes in Göttingen. Archives of Natural History 26: 157-203.

Zilch A. 1959. Gastropoda, Euthyneura. In: Schindewolf O.H. (ed.) Handbuch der Paläozoologie, Volume 6: 1-400. Gebrüder Borntraeger, Berlin.

Manuscript received: 28 February 2020

Manuscript accepted: 13 May 2020

Published on: 25 June 2020

Topic editor: Rudy Jocqué

Section editor: Thierry Backeljau

Desk editor: Eva-Maria Levermann

Printed versions of all papers are also deposited in the libraries of the institutes that are members of the EJT consortium: Muséum national d'histoire naturelle, Paris, France; Meise Botanic Garden, Belgium; Royal Museum for Central Africa, Tervuren, Belgium; Royal Belgian Institute of Natural Sciences, Brussels, Belgium; Natural History Museum of Denmark, Copenhagen, Denmark; Naturalis Biodiversity Center, Leiden, the Netherlands; Museo Nacional de Ciencias Naturales-CSIC, Madrid, Spain; Real Jardín Botánico de Madrid CSIC, Spain; Zoological Research Museum Alexander Koenig, Bonn, Germany; National Museum, Prague, Czech Republic. 